\title{
The Effect of Various Restorative Materials on the Microhardness of Reparative Dentin
}

CHARLES F. COX, DONALD R. HEYS, P. KENT GIBBONS, JAMES K. AVERY, and RONALD J. HEYS

Laboratory of Oral Histology, Dental Research Institute, The University of Michigan, Ann Arbor, Michigan 48109

This study showed a statistically significant difference between the microhardness of reparative and primary dentin at both five-and eight-week intervals. Reparative dentin from occlusal trauma is harder than reparative dentin underlying a cavity preparation at the $99 \%$ level. No statistical difference was noted in the hardness of reparative dentin underlying different materials, but trends were observed.

\section{J Dent Res 59(2):109-115, February 1980}

\section{Introduction.}

Dentin which is deposited after primary (mantle) dentinogenesis has been defined by Sicher ${ }^{1}$ as two types or kinds. Secondary dentin is deposited over the entire innercircumpulpal surface throughout the life of the tooth. Reparative dentin is deposited as a response or reaction to extensive occlusal wear, erosion, caries, and clinical operative procedures. Mjör ${ }^{2}$ later observed and defined the preferential deposition of secondary dentin based on the nature of tubule continuity. One type of regular secondary dentin is seen over the entire pulpal surface of coronal dentin, while the other more irregular type is restricted, as to time of deposition and continuity of tubules from, or through, primary to secondary dentin. This further definition of secondary dentin allows all other dentin which appears in response to damage or destruction to be referred to as reparative dentin.

The hardness of dentin and enamel has been studied by a number of investigators using several methods. Early studies by Hodge $^{3}$ evaluated various procedures to measure the hardness of tooth tissue. The tests varied from scratching, indentation, elastic impact, cutting, and permanent deformation. Most of these tests, however, destroyed the tissue, thus distorting the gradient factors of measurement. Burg ${ }^{4}$

Received for publication December 19, 1978. Accepted for publication February 15, 1979. and Richter ${ }^{5}$ reported conflicting differences of enamel hardness, carious and non-carious dentin in pregnant and non-pregnant women. Investigative studies by Gustafson ${ }^{6}$ showed that two similar indentation tests on ground tooth tissues revealed that differences in hardness may be due to specific structural characteristics of each tooth tissue, e.g. sclerosis, age, or caries. He reported that tufts and spindles are lower in density (hardness) than adjacent enamel.

More recent studies by $\mathrm{Craig}^{7,8}$ utilized the physical indentation test of "Knoop" (KHN) on ground sections of human teeth to establish trends in hardness from one tooth tissue to another. The average $\mathrm{KHN}$ of enamel was 343, and 68 for dentin. One study ${ }^{7}$ stated that no trends could be detected between tooth types and that no hardness differences existed from the dentin enamel junction (DEJ) to the outer enamel surface. A later study ${ }^{8}$ showed that transparent dentin had an average KHN of 80 , while carious dentin had an average $\mathrm{KHN}$ of 25 .

Other techniques of evaluation $9,10 \mathrm{em}$ ployed microradiography of tooth tissue using $\mathrm{x}$-rays, noting a progressive loss of calcium in the carious lesion. Mjör ${ }^{11}$ reported an increased mineral content of the calcium-hydroxide covered dentin in the surface layer of dentin exposed to the oral environment, which he felt was due to the precipitation of mineral salts. With this information, it is of clinical interest for dentists to know if the reparative dentin which forms under restorative materials will vary with the material used.

Independent studies $^{12,13}$ noted that the rate of human reparative dentin formation is initially highest and decreases with time; however, Stanley ${ }^{12}$ reported that the milder the insult to the tooth, the longer the period of time before reparative dentin deposition begins. Another study ${ }^{14}$ on rats reported that the deeper the cavity preparation (less 
remaining dentin), the poorer the quality of reparative dentin. The study also reported that the KHN of dentin decreased almost linearly from the dentinoenamel junction towards the pulpo-dentinal interface, and that reparative dentin bridges which formed in pulp-capped rat incisors were less hard than the initially deposited primary dentin.

\section{Materials and methods.}

This study is based on the examination of human extracted teeth and the teeth from one rhesus (Macaca mulatta) monkey. A series of extracted human teeth containing Class $\mathrm{V}$ restorations of amalgam, silicates and composites, some of which had bases, were collected and preserved in a solution of water. ${ }^{15}$

The human teeth were halved with a fissure bur to expose the pulpal aspect of reparative dentin; next, the teeth were sectioned, longitudinally, through the restoration and area of reparative dentin, using a silicon carbide disc. The teeth were then embedded in Ward's Bioplastic, polished with 600 Grade abrasive paper, and finished with $15 \mu$ alumina compound.

Class $V$ cavities were placed on the noncarious buccal surface of rhesus monkey teeth at a standard depth of approximately 0.5 millimeters of remaining dentin with a high speed turbine $(250,000$ RPM) with water and air spray, using a new \#35 carbide inverted cone bur. The cavities were filled with either amalgam, composite, silicate, or calcium hydroxide plus amalgam filling materials. These materials remained in the teeth for periods of five and eight weeks before removal according to the A.D.A. Committee on Materials and Devices, $\mathrm{MD}$ 156.

The monkey was sedated under general anesthesia using sodium pentobarbital. Using vascular perfusion, ${ }^{16}$ saline was employed to flush the vessels clear of blood, and alcohol formalin acetic acid fixative was introduced into the vascular system. The monkey teeth were prepared in the same manner as the human teeth.

The microhardness test was done on a "MQ" Tukon Microhardness tester with a Knoop diamond indenter. A 25-gram load was used to make the indentations with a 15 -second indentation contact time used throughout the study. A $4.0 \mathrm{~mm}$ objective was used to measure the length of the indentation. All tooth samples were kept in water until measured, since other studies ${ }^{15}$ have shown that dry storage increases the hardness.

Three areas of dentin were selected for $\mathrm{KHN}$ testing on each tooth sample. A series of six indentation KHN tests were made in each of the three areas. The three areas of dentin tested were primary dentin uncut by the preparation, remaining dentin lying directly under the restoration, and reparative dentin formed due to the restorative procedures. In a few of the monkey teeth, reparative dentin which had formed due to occlusal irritation was also tested for $\mathrm{KHN}$. The series of six indentations in each area of one tooth were averaged, and the mean was used to represent the hardness number for that area of the tooth. The indentations measured were converted into Knoop hardness numbers.

Differences between experimental groups were compared by means of Student's ttest.

\section{Results.}

KHN of human dentin. - The results of Knoop microhardness testing on 17 restored human carious teeth may be seen in Table I. In all but one case tested, the KHN of the remaining dentin was less (45.66) than the KHN of uncut dentin (61.44) of the same tooth. Likewise, each individual tooth tested a lower KHN for reparative dentin (40.5) as compared to its uncut KHN data. In comparing the individual KHN of human reparative dentin to remaining dentin, four of 16 teeth had only a slightly higher individual reparative KHN number from the same tooth. Eleven teeth had rather significant decreased KHN readings of reparative dentin when compared to KHN of remaining dentin on the same teeth. The pairwise t-statistics for human teeth (seen in Table II) show a statistically significant difference in KHN between the remaining dentin under restorations and reparative dentin, when compared with uncut primary dentin in the same tooth. The uncut primary dentin showed the hardest KHN.

In most of the human teeth examined, there was discoloration of the dentin under the restorative materials (Fig. 1). This was 
TABLE I

MEAN MICROHARDNESS OF RESTORED CARIOUS HUMAN TEETH

\begin{tabular}{cccc}
\hline \hline $\begin{array}{c}\text { Case } \\
\text { Number }\end{array}$ & $\begin{array}{c}\text { KHN of } \\
\text { Uncut } \\
\text { Dentin }\end{array}$ & $\begin{array}{c}\text { KHN of } \\
\text { Remaining } \\
\text { Dentin }\end{array}$ & $\begin{array}{c}\text { KHN of } \\
\text { Reparative } \\
\text { Dentin }\end{array}$ \\
\hline 1-A & 61.43 & 38.64 & 36.87 \\
2-C & 60.7 & 32.87 & 34.25 \\
3-C & 68.41 & 49.78 & 39.21 \\
4-A & 65.5 & 36.81 & 37.48 \\
5-C & 62.67 & 43.17 & 43.26 \\
6-A & 63.72 & 55.20 & 44.24 \\
7-C & 64.11 & 48.26 & 45.55 \\
8-A & 65.9 & 57.94 & 49.17 \\
9-C & 64.51 & 42.70 & 42.70 \\
10-C & 54.22 & 30.42 & 34.64 \\
11-A & 61.08 & 36.17 & 35.84 \\
12-C & 62.52 & 52.13 & 28.53 \\
13-A & 47.47 & 38.37 & 31.15 \\
14-A & 62.43 & 60.73 & 54.38 \\
15-C & 51.83 & 55.67 & 41.99 \\
16-A & 68.61 & & 43.66 \\
17-C & 60.37 & 51.7 & 45.66 \\
& & & \\
\hline & mean $=$ & mean & mean $=$ \\
& 61.44 & 45.66 & 40.5
\end{tabular}

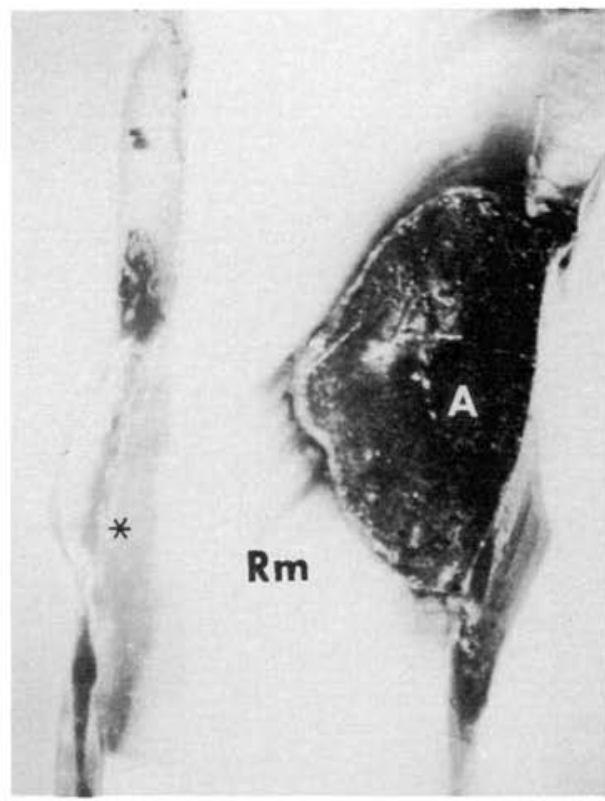

Fig. 1 - Photograph of an amalgam (A) restoration from a human tooth. The remaining dentin $(\mathrm{Rm})$ directly below the restoration, and extending pulpally, shows areas of discoloration. The reparative dentin $\left(^{*}\right)$ is also slightly discolored.

TABLE II

PAIRWISE T-STATISTICS FOR HUMAN TEETH

\begin{tabular}{lccccc}
\hline \hline \multicolumn{1}{c}{ DENTIN TESTED } & $\begin{array}{l}\text { Mean } \\
\text { KHN }\end{array}$ & $\begin{array}{c}\text { Mean KHN } \\
\text { Differences }\end{array}$ & STD DEV & T-stat. & Significance \\
\hline Uncut Dentin & 61.44 & 15.78 & 9.57 & 6.4 & $100 \%$ \\
Remaining Dentin & 45.66 & $\mathrm{~N}=16$ & & & \\
Uncut Dentin & 61.44 & 20.93 & 6.82 & 12.6 & $100 \%$ \\
Reparative Dentin & 40.50 & $\mathrm{~N}=17$ & & & \\
Remaining Dentin & 45.66 & 5.16 & 7.0 & 3.0 & $99 \%$ \\
Reparative Dentin & 40.50 & $\mathrm{~N}=6$ & & & \\
\hline
\end{tabular}

especially true of teeth restored with amalgam. The area of discolored dentin followed the course of the dentinal tubules from the restorative material through the remaining dentin to the pulp. In some cases the reparative dentin itself was discolored and looked as if it had picked up products from the restorative material. None of the monkey teeth examined showed any sign of discoloration.

Due to the restorative procedure, the area of the pulp where reparative dentin formed was limited to the area adjacent to dentin whose tubules had been cut by the cavity preparation.

KHN of monkey dentin. - The results of Knoop microhardness testing on monkey teeth may be seen in Table III. The total cumulative means for all compounds show a difference in $\mathrm{KHN}$ between the remaining dentin under restorations and reparative dentin, when compared with uncut primary dentin in the same tooth. In 17 of 22 teeth, the KHN of uncut dentin was higher than the KHN of remaining dentin. In each specimen the $\mathrm{KHN}$ of the reparative dentin 
TABLE III

MEAN MICROHARDNESS OF MONKEY TEETH

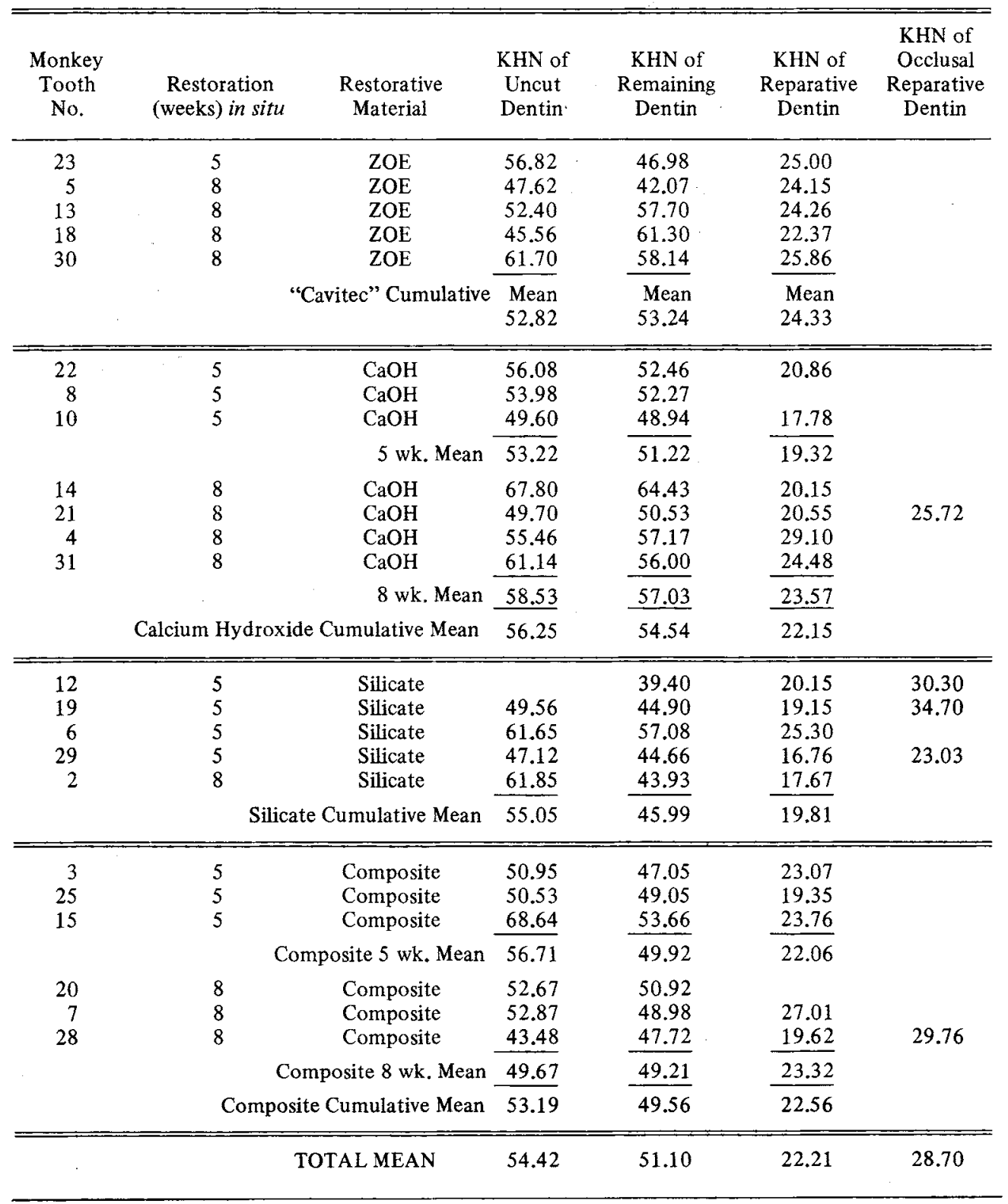

was considerably less than that for either uncut or remaining dentin. Those five teeth in which the occlusal remaining dentin was measured always showed a higher (harder) reading than reparative dentin in the same tooth; however, the occlusal dentin was always lower (softer) than either the remaining or uncut dentin.
Generally the total overall means show trends as follows:

KHN of Uncut Dentin 54.42

KHN of Remaining Dentin 51.10

KHN of Reparative Dentin 22.21

KHN of Occlusal Reparative Dentin 28.70

The nature of sampling for the various groups precludes statistical analysis. How- 
ever, note that the $\mathrm{KHN}$ of remaining dentin for calcium hydroxide at eight weeks is slightly higher than at five weeks.

A comparison of $\mathrm{KHN}$ of human dentin to that of monkey dentin showed a difference in KHN for all three types of dentin as seen below.

\begin{tabular}{lccc}
\hline & $\begin{array}{c}\text { KHN of } \\
\text { Uncut } \\
\text { Dentin }\end{array}$ & $\begin{array}{c}\text { KHN of } \\
\text { Remaining } \\
\text { Dentin }\end{array}$ & $\begin{array}{c}\text { KHN of } \\
\text { Reparative } \\
\text { Dentin }\end{array}$ \\
Human & 61.44 & 45.66 & 40.50 \\
Monkey & 54.42 & 51.10 & 22.21 \\
\hline
\end{tabular}

Due to the variables in materials and time of placement in human teeth, however, it is impossible to draw significant differences between the human and monkey studies.

\begin{tabular}{|c|c|c|}
\hline \multicolumn{3}{|c|}{$\begin{array}{c}\text { TABLE IV } \\
\text { MEAN KHN FOR REMAINING DENTIN IN } \\
\text { MONKEY TEETH }\end{array}$} \\
\hline Material & Mean KHN & STD DEV \\
\hline ZOE & 53.24 & 8.2 \\
\hline $\mathrm{CaOH}$ & 54.54 & 5.2 \\
\hline Silicate & 45.99 & 6.5 \\
\hline Composite & 49.56 & 2.4 \\
\hline
\end{tabular}

MEAN KHN FOR REPARATIVE DENTIN IN MONKEY TEETH

\begin{tabular}{lcc}
\hline \multicolumn{1}{r}{ Material } & Mean KHN & STD DEV. \\
\hline Composite & 22.56 & 3.1 \\
Silicate & 19.81 & 3.3 \\
ZOE & 24.33 & 1.29 \\
$\mathrm{CaOH}$ & 22.15 & 4.0
\end{tabular}

The difference in hardness when comparing uncut dentin and remaining dentin under restorations in monkey teeth was not statistically significant, as seen in Table IV. A significant difference in hardness was found (Table V) when uncut dentin was compared with both types of reparative dentin in monkey teeth. The hardness of reparative dentin, formed from occlusal irritation, was found to be significantly harder than the reparative dentin formed due to restorative procedures.

\section{Discussion.}

Many of the previous studies $1,7,9,17$ have stated that the hardness of dentin under a filling is of a different hardness than other dentin. However, many of these authors have not attempted to elaborate on these correlations, i.e., density of remaining dentin, reparative dentin, dentin bridge formation, or changes in hardness of dentin as a factor of time. Microradiographic studies by Skogedal ${ }^{10}$ showed a decreased microdensity in remaining dentin, while Mjör ${ }^{11}$ reported an increased microdensity under the dentinal tubules of the remaining dentin with a calcium hydroxide material. A microhardness study by Fusayama, ${ }^{18}$ however, showed no difference in the hardness of root dentin with root canals filled with calcium hydroxide, or of those teeth with root canals left open to the oral environment. In deference to Mjör's ${ }^{11}$ study, Fusayama ${ }^{18}$ reported that the inner dentin (pulp) walls, or open pulps, neither softened nor became harder when the cavity was

TABLE $V$

PAIRWISE T STATISTICS FOR MONKEY TEETH

\begin{tabular}{lccccc}
\hline \multicolumn{1}{c}{ DENTIN TESTED } & Mean & $\begin{array}{c}\text { Mean } \\
\text { Differences }\end{array}$ & STD DEV & T-stat. & Significance \\
\hline Uncut Dentin & 54.4 & 2.78 & 6.7 & 1.9 & $93 \%$ \\
Remaining Dentin & 51.6 & $\mathrm{~N}=22$ & & & \\
Uncut Dentin & 54.5 & 32.2 & 7.0 & 20.3 & $100 \%$ \\
$\begin{array}{l}\text { Reparative Dentin } \\
\text { Uncut Dentin }\end{array}$ & 22.3 & $\mathrm{~N}=20$ & & & \\
$\begin{array}{l}\text { Occlusal Reparative } \\
\text { Dentin }\end{array}$ & 47.4 & 19.1 & 5.64 & 6.7 & $99 \%$ \\
$\begin{array}{l}\text { Reparative Dentin } \\
\text { Occlusal Reparative }\end{array}$ & 28.3 & $\mathrm{~N}=4$ & & & \\
$\quad$ Dentin & 19.24 & $\begin{array}{c}-9.4 \\
\mathrm{~N}=5\end{array}$ & 4.0 & -5.18 & $99 \%$ \\
& 28.7 & & & &
\end{tabular}


filled with calcium hydroxide. Microhardness tests by Luostarinen ${ }^{14}$ showed that reparative dentin formed after trauma was less hard than secondary dentin of control teeth. Our laboratory studies (Avery ${ }^{19}$ ) agree with Luostarinen that when a dentin bridge is initially formed, the initial matrix is deposited at such a fast rate that its mineralization phase is less complete; however, no KHN correlation has ever been studied of either new dentin bridge formation or reparative dentin over a period of time (reflected in thickness). Our results suggest that, as either the dentin bridge or reparative dentin becomes thicker, it increases in KHN. Perhaps a more definitive measurement would be to utilize the microanalytical techniques of Takuma, ${ }^{20}$ in which he reported an increased concentration of sulfur in rat osteodentin interfibrillar ground substance over that found in normal dentin matrix.

\section{Conclusions.}

The microhardness results in this study have shown conclusively that reparative dentin formed as a result of the various restorative procedures is less hard than the primary dentin in the same tooth. The decrease in KHN of the remaining dentin under restorations in human teeth, compared to their adjacent primary dentin, may be due to the fact that the human teeth were carious to begin with. A small and insignificant decrease in $\mathrm{KHN}$ of the remaining dentin under the restorations in the monkey teeth, as compared with the primary dentin, was observed. This may indicate that the restorative materials tested did not affect the KHN of the remaining dentin under them, although the five- and eight-week periods that the restorations were present in the teeth may not have been long enough to produce a change in hardness. The method of testing KHN and the small sample size used may not have made it possible to determine a small but significant change in hardness.

This experiment was not able to show any significant difference in the hardness of reparative dentin formed under different restorative materials; however, this may be due to the method of testing and sample size. It is also possible that the method of cavity preparation is the main factor deter- mining the quality of reparative dentin formed. This may overshadow any effect caused by the restorative material.

Discoloration of dentin under restorations in human teeth, but not in monkey teeth, may be due to the presence of the restoration in the human teeth for a longer period of time. All of the human teeth were stored in a solution of glycerin and alcohol, while the monkey teeth were not. This may also be a factor affecting discoloration.

\section{REFERENCES}

1. SICHER, H.: Orban's Oral Histology and Embryology, 5th ed., St. Louis: C.V. Mosby Co., 1962, pp. 120-125.

2. MJÖR, I.A.: The Structure of Normal and Experimentally Altered Coronal Dentine, A Symposium on Dentine and Pulp: Their Structure and Reactions, Ed. Dundee: B.B. Symons Co., 1967. pp. 83-113.

3. HODGE, H.C and McKAY, H.: The Microhardness of Teeth, JADA 20:2, 227-233, 1933.

4. BURG, F.: Neue Spezielle Härtebestimmungen der Hartsubstanzen des Zahnes, Dissertation, Jena, 1921.

5. RICHTER, H.: Härteprufung an Schmelz und Dentine II, Ztschr Stomatol 29:591606, 1931.

6. GUSTAFSON, G. and KLING, O.: MicroHardness Measurements in the Human Dental Enamel, Odont Tidskrift 56:1, 24-44, 1948.

7. CRAIG, R.G. and PEYTON, F.A.: The Microhardness of Enamel and Dentin, $J$ Dent Res 37:661-668, 1958.

8. CRAIG, R.G.; GEHRING, P.E.; and PEYTON, F.A.: Relation of Structure to the Microhardness of Human Dentin, $J$ Dent Res 38:624-630, 1959.

9. WYCKOFF, R.W.G. and CROISSANT, O.: Microradiography of Dentine Using Characteristic X-rays, Biochemica et Biophysica Acta 66:137-143, 1963.

10. SKOGEDAL, $O$, and TRONSTAD, L.: An Attempt to Correlate Dentin and Pulp Changes in Human Carious Teeth, Oral Surg 43(1):135-140, 1977.

11. MJOR, I.A.: The Structure of Normal and Experimentally Altered Coronal Dentine, Dentine and Pulp - Their Structure and Reactions, Ed., Dundee: B. B. Symons Co., 1968 , pp. 83-99.

12. STANLEY, H.: The Rate of Tertiary (Reparative) Dentin Formation in the Human Tooth, Oral Path $21:(2): 180-189,1966$.

13. GOTO, G.: The Rate of Reparative Dentin Formation in the Human Deciduous Teeth, Bull Tokyo Dent Coll 13:251-256, 1972.

14. LUOSTARINEN, V.: Dental Pulp Response to Trauma: An Experimental Study in the 
Rat, Suom Hammasläak Toim, Suppl. II 67:7-51,1971.

15. YODER, E.C.: Effect of Storage Media on the Roughness and Hardness of Root Dentin, Dissertation, Univ. of Mich., Ann Arbor, 1968.

16. COX, C.F.; HEYS, D.R.; and HEYS, R.J.: A Gravity Perfusion Technique for Lab Animals, Lab Animal 6(4):18-22, Jul-Aug 1977.

17. MASSLER, M.: Biologic Considerations in the Selection and Use of Restorative Materials, Dental Clinics of North America, March, 131-147, 1965.
18. FUSAYAMA, T and MAEDA, T.: Effect of Pulpectomy on Dentin Hardness, $J$ Dent Res 48:(3):452-460, 1969.

19. AVERY, J.K.: Theories of Mechanisms of Dentinal Bridge Formation. Pulp Biology Symposium I, 56th General Session, I.A.D.R., Washington, D.C., 1978.

20. TAKUMA, S.; YANAGISAWA, T.; and LIN, W.L.: Ultrastructural and Microanalytical Aspects of Developing Osteodentin in Rat Incisors, Calcif Tiss Res 24:215-222, 1977.

\section{FIRST WORLD BIOMATERIALS CONGRESS}

BADEN near VIENNA, April 8-12, 1980

Information: World Biomaterials Congress Secretariat

Mrs. E. Maurer

Medical Academy of Vienna

Alser Strasse 4

A-1090 VIENNA, Austria

Tel. (0222) 427165

Cables: Medacad Wien

The program of the FIRST WORLD BIOMATERIALS CONGRESS will interest all scientists, engineers, and clinicians working in this interdisciplinary field. The purpose of the conference, which is being organized by the European Society for Biomaterials, the Society for Biomaterials (USA) and the Biomaterials Group of the Biological Engineering Society (UK), is to provide an opportunity for those interested in biomaterials, worldwide, to meet together and exchange information about their activities. The official language of the Congress will be English.

The conference will review the achievements, outstanding problems and future trends of biomaterials science. 